\title{
Influence of Shunting Current on the Metallurgical and Mechanical Behaviour of Resistance Spot-welded Joints in AA2219 Joints
}

\author{
Mehdi Jafari Vardanjani1 1,* - Alireza Araee ${ }^{1}$ - Jacek Senkara ${ }^{2}$ - Majid Sohrabian ${ }^{3}$ - Roozbeh Zarandooz ${ }^{4}$ \\ 1 University of Tehran, Department of Mechanical Engineering, Iran \\ 2 Warsaw University of Technology, Department of Welding Engineering, Poland \\ 3 University of Science \& Technology, Department of Mechanical Engineering, Iran \\ ${ }_{4}^{4}$ Arak University of Technology, Department of Mechanical Engineering, Iran
}

The effects of shunting current on metallurgical and mechanical behavior of resistance spot-welded (RSW) joints in AA2219 sheets are analysed experimentally via the investigation of mechanical and metallurgical properties, while numerical results predicted by the finite element method (FEM) are used to check the thermal aspects of the phenomenon and its effect on experimental results. Welding distance is chosen as the main variable for two consecutive nuggets. Predicted temperature distribution and cooling rates of FEM are verified by checking the nuggets and heat-affected zone (HAZ) dimensions, the SEM investigation of cracks, and performing a tensile-shear test. Experimental results have been in agreement with the predicted results, since HAZ development, the presence of cracks, interfacial failure, and poor mechanical strength of shunted nugget with shorter welding distance are all predicted in the form of temperature distribution and cooling rates of shunted nugget in finite element analysis (FEA). The temperature dependence of material properties and coupling between all aspects of the solution are respected in the FEA model while experimental tests are performed according to a three-factor design of experiment (DOE) to set the levels of factors based on their significance.

Keywords: shunting effect; heat affected zone; tensile-shear strength; failure type; finite element method

Highlights

- Shunting effect of RSW is considered for the brittleness of joints, and FEM results are used to check thermal effects of the phenomenon on metallurgical and mechanical behaviour.

- Distance effect of the shunting current was clearly observable on tensile-shear strength.

- Experimental and numerical results proved a shunting effect on crack generation.

- HAZ asymmetry due to shunting effect was observed experimentally and numerically.

- Influence of welding distance was discovered for the failure type in tensile-shear strength.

\section{INTRODUCTION}

Shunting current appears in resistance spot-welds (RSW) when there is a secondary circuit next to main welding current. This circuit is usually provided by previous spot(s), therefore a fraction of the applied welding current passes via previous welding spot(s). This phenomenon alternates metallurgical and mechanical qualities of the current spot due to changes in electrical and temperature distributions. Parameters affecting this phenomenon include welding distance, number, and size of previous nuggets, surface roughness, and electrode force. This phenomenon occurs in many industries requiring intermittent joints made by RSW. One of the significant industries including this type of joints is aerospace industry in which AA2219 is a common alloy used to produce many parts of products, such as fuselages and so on. The reliable mechanical and metallurgical quality of these joints are necessary for the final performance of products. Therefore, assuring the final quality of intermittent RSW joints is inevitable in such industries. This proves the necessity of experimental and analytical consideration of the shunting effect on welding nuggets to optimize parameters and avoid undesirable consequences, particularly regarding the mechanical and metallurgical quality of the final product. In addition, regardless of the shunting effect, the comparison of failure load values obtained using the RSW process and other joining methods such as riveting of steel sheets by Zeyveli et al. [1] in which the maximum strength of $2.747 \mathrm{kN}$ was obtained (which is less than the values usually obtained for RSW of aluminum alloys), demonstrates the importance of considering RSW and its associated issues to solve, rather other similar joining processes.

One of the oldest experimental studies of the shunting effect was performed by Hard [2] who provided a method for detecting shunting paths. Sheet size, weld spacing, electrode geometry, and electrode force were considered in the following studies to find minimum required distance of shunting effect [3]. 
The effect of shunting current on crack generation in RSW of AA5754 (Senkara and Zhang [4] and Zhang et al. [5]) was observed as the side effects of multiple spot welding, while the necessity and requirement of deeper investigation on the influence of shunting current on mechanical aspects of shunted spots was proved as a result. The effect of surface quality was checked by Howe [6] and Wang et al. [7] to observe the effect of surface conditions on shunting intensity.

Modeling and theoretical approaches to consider shunting effects have been numerable due to difficulty in the asymmetric configuration of the shunted nugget model, and assigning appropriate properties to the previous (shunting) spot, if two adjacent nuggets were to be analyzed; however, the electrical, thermal, and mechanical principles are similar, regardless of the configuration of the problem.

Among the most important numerical studies are a 3D finite element analysis (FEA) by Chang and Cho [3], in which electrical and thermal parameters were predicted in a shunted nugget or a theoretical model developed by Li et al. [8], to obtain the minimum required welding distance. The latter case was designed based on many geometrical simplifying assumptions. Simulation of temperature and electrical potential distribution (Tsai et al. [9]), prediction of contact radius (Shen et al. [10]), nugget formation and deformations (Nied [11]), and coupled analysis of RSW process (Zhang [12] and Kim et al. [13]) are examples of general FEA on asymmetric configuration of a single spot.

In this paper, the influence of shunting current on metallurgical and mechanical behaviour of resistance spot welded joints in AA2219 joints is analyzed experimentally by investigation of mechanical and metallurgical behaviour while numerical results predicted by the finite element method (FEM) are used to check thermal aspects of the phenomenon and its effects on experimental results. Welding distance is chosen as the main variable for two consecutive nuggets. Predicted temperature distribution and cooling rates of FEM indicate the heat-affected zone (HAZ) distribution toward previous spot and brittle structure with poor tensile-shear strength respectively, for shorter welding distances. Both of these predictions are verified by checking the nugget and HAZ dimensions, tensile-shear test, and SEM consideration of samples, revealing the presence of cracks, poorer mechanical strength, and interfacial failure of shunted nuggets with shortened welding distances.

\section{METHODS}

FEA and experiments performed are described here separately.

\subsection{Finite Element Analysis}

Mathematical equations, the configuration of the model, and the material properties used in FEM are described in this section.

\subsubsection{Mathematical Equations}

Electrical and thermal equations plus boundary conditions are explained in a distinguished manner here.

\subsubsection{Electrical Equations}

Quasi-Laplace equation of electrical potential $\phi$, can be written in $3 \mathrm{D}$ coordinates as [2]:

$$
\frac{\partial}{\partial x}\left[\frac{1}{\rho} \cdot \frac{\partial \phi}{\partial x}\right]+\frac{\partial}{\partial y}\left[\frac{1}{\rho} \cdot \frac{\partial \phi}{\partial y}\right]+\frac{\partial}{\partial z}\left[\frac{1}{\rho} \cdot \frac{\partial \phi}{\partial z}\right]=0,
$$

where $\rho$ is the bulk electrical resistivity. Boundary conditions are provided in Table A1 according to Fig.

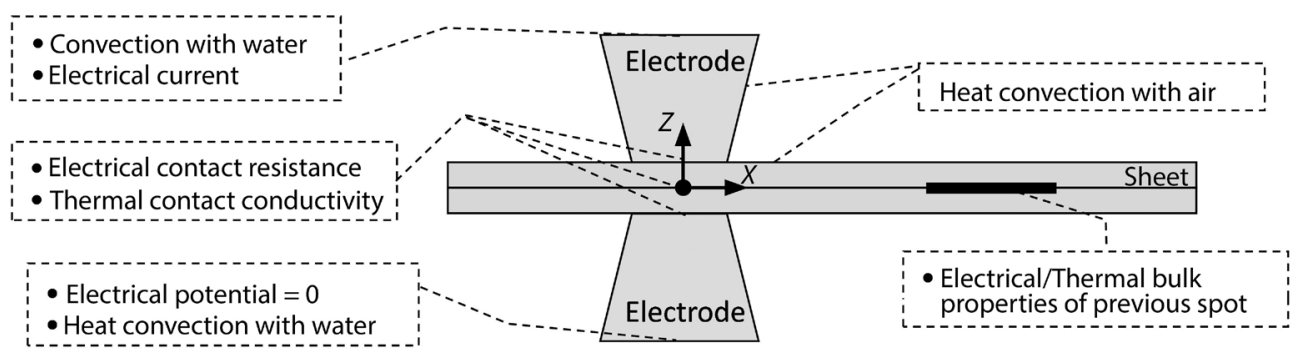

Fig. 1. Schematics for boundary conditions and important domains 
1. For the application of the alternative current, it can be assumed that [14]:

$$
I_{e}=\frac{I_{p}}{\sqrt{2}}
$$

where $I_{e}$ is the applied eletrical current on electrode and $I_{p}$ is the maximum electrical current supplied in the welding machine. Eq. (3) is used to calculate electrical contact resistivity [14].

$$
\rho_{C}(T)=R_{C}\left(20^{\circ} \mathrm{C}\right) \cdot \frac{A_{C}}{L_{C}} \sqrt{\frac{\sigma_{e, a v e}(T)}{\sigma_{e, a v e}\left(20^{\circ} \mathrm{C}\right)}},
$$

where $R_{C}\left(20^{\circ} \mathrm{C}\right)$ is the measured electrical contact resistance (ECR) of the electrode-sheet interface at $20^{\circ} \mathrm{C}$ under constant mechanical pressure, $L_{C}$ is the characteristic thickness of contact surfaces (assumed equal to $1 \times 10^{-4}$ for some aluminium alloys as reported by Sun and Dong [15]), $A_{C}$ is the nominal contact area, $\sigma_{e, \text { ave }}(T)$ and $\sigma_{e, a v e}\left(20^{\circ} \mathrm{C}\right)$ are the average yield stress of contacting materials at $T$ and $20^{\circ} \mathrm{C}$ respectively.

\subsubsection{Thermal Equations}

The thermal equation is presented in Eq. (4) [2] and [16].

$$
\begin{aligned}
D \cdot c \cdot \frac{\partial T}{\partial t} & =\frac{\partial}{\partial x}\left[k \cdot \frac{\partial T}{\partial x}\right]+\frac{\partial}{\partial y}\left[k \cdot \frac{\partial T}{\partial y}\right]+ \\
& +\frac{\partial}{\partial z}\left[k \cdot \frac{\partial T}{\partial z}\right]+\frac{1}{\rho} \nabla \phi \cdot \nabla \phi,
\end{aligned}
$$

where $D$ is mass density, $c$ is specific heat capacity, $k$ is thermal conductivity coefficient, and $T$ is temperature. Specific heat capacity after melting temperature (phase change) $\left(c_{w}\right)$ follows Eq. (5) [3].

$$
c_{w}=\frac{H_{m}}{T_{l}-T_{s}},
$$

where $H_{m}$ is fusion latent heat, and $T_{s}$ and $T_{l}$ are solidus and liquidus temperatures, respectively. Thermal boundary conditions are provided in Table A2.

Thermal contact conductivity (TCC) coefficients are calculated using Eq. (6) as reported by Zhang and Senkara [17].

$$
k_{c}=\frac{1}{3}\left(\frac{\sigma}{\sigma_{e}}\right)\left(\frac{k_{1}+k_{2}}{2}\right),
$$

where $k_{c}$ is the TCC coefficient, $\sigma$ is normal stress, $\sigma_{e}$ is yield stress, and $k_{1}$ and $k_{2}$ are the TCC coefficient of contacting parts.

\subsubsection{Configuration of the Model}

To simplify the calculation process, the previous nugget is defined as a cylindrical connection between the two sheets (Fig. 2) and the diameter is specified according to the dimensions of an experimental nugget, obtained using average welding parameters in single spot welding.

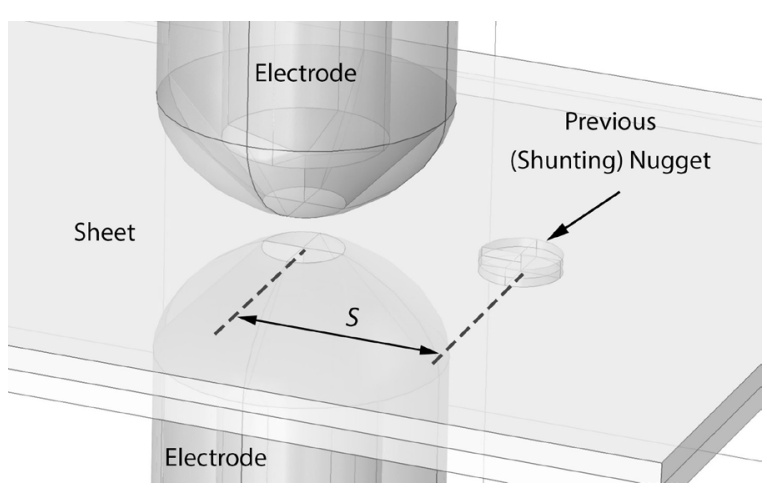

Fig. 2. Welding configuration, showing shunting (previous) nugget and other parts in FEM model

\subsubsection{Material Properties}

The elastic-plastic material is specified as the type of material for AA2219 in the model. The composition of the alloy is identified by a scanning electron microscope (SEM) at different points on the sample, as shown in Table B1. Tables B2 and B3 provide important properties of AA2219. Table B4 provides important properties of $\mathrm{C} 18150$ as the material used for electrodes. Table B5 indicates important electrical and mechanical properties of the shunting nugget. Since the temperature of the nugget does not change drastically during the process, ambient temperature properties are assigned. Therefore, the thermal properties of the shunting nugget are also defined as the same as the sheet alloy. Table B6 shows electrical contact resistance (ECR) values measured at room temperature. Electrical resistances are measured experimentally using the method reported by Vogler and Sheppard [18] while mechanical properties were determined by performing micro-hardness and extraction of elasticity modulus and yield strength, reported by nano-indentor. All of these material properties are used in the FEA process as temperature dependent or independent properties according to the parameter's formula.

The melting process is modelled using phase change capability in multi-physics simulation software (COMSOL). Both solid and liquid phases were defined 
in the software to achieve a reliable simulation, while material properties changed according to temperature and phase state (Table B2). Therefore, the behaviour of the molten alloy was different from the solid state as some of the properties changed after the phase change. For instance, the strength of material reaches the minimum value according to material properties in high temperature (liquid state), or specific heat capacity changes according to Eq. (5); however, the liquid properties, such as viscosity or fluidity, were ignored since the liquid state appears for a very short time and does not considerably influence the progress of the simulation. Therefore, it is reasonable to ignore such properties as other studies such as [15] and [19] included similar assumptions for finite element analysis of the melting process.

\subsection{Experiments}

Weldability tests, the design of experiment (DOE), metallographic considerations, and tensile-shear tests are the main phases of the experiments. Principles of coupon preparation, inspection of results, as well as the preheating and welding parameters, were excerpted from military and welding handbooks [20] and [21]. 12 $\mathrm{kA}$ and 4 cycles was chosen for preheating, while the off time was 2 cycles. The squeeze and holding forces were $2 \mathrm{kN}$ and $3.2 \mathrm{kN}$ respectively. The initial range of welding current, time, and force for DOE were 22 $\mathrm{kA}$ to $26 \mathrm{kA}, 2$ cycles to 10 cycles, and $2.5 \mathrm{kN}$ to 3.2 $\mathrm{kN}$ respectively. Electrode was chosen as dome type according to previous studies [21] (Fig. 3).

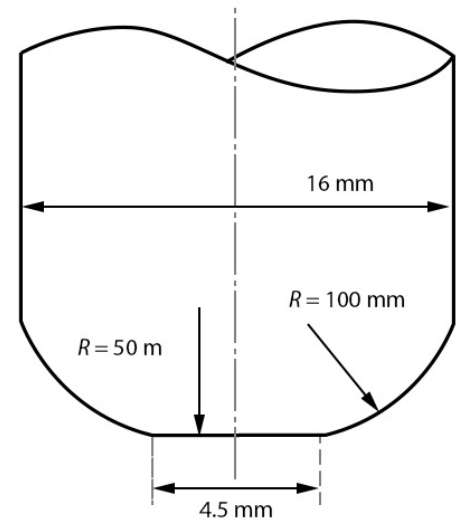

Fig. 3. Geometry of electrodes

\subsubsection{Weldability Tests}

The weldability window was obtained (Fig. 4) after finding the allowable electrode force to provide an expulsion-free nugget diameter between $3.5 \sqrt{t_{s}}$ and $3.5 \sqrt{t_{s}}$ [20] and [23] where $t_{s}$ is sheet thickness [21].

\subsubsection{Design of Experiments (DOE)}

Three-factor DOE was performed in a rectangular area inside the welding lobe for both nugget diameter and failure load, while the welding distance range was set according to a previous study by Howe [6] (Table 1). Figs. 5 and 6 show schematic and real samples after welding, respectively. Spot $S_{1}$ (shunting spot) on all samples was welded using the average parameters provided in Table 2. The electrode force was set to $2900 \mathrm{kN}$ for all tests according to previous study [24]. After welding the procedure, the specimens were cut through the spots for geometrical and metallurgical considerations.

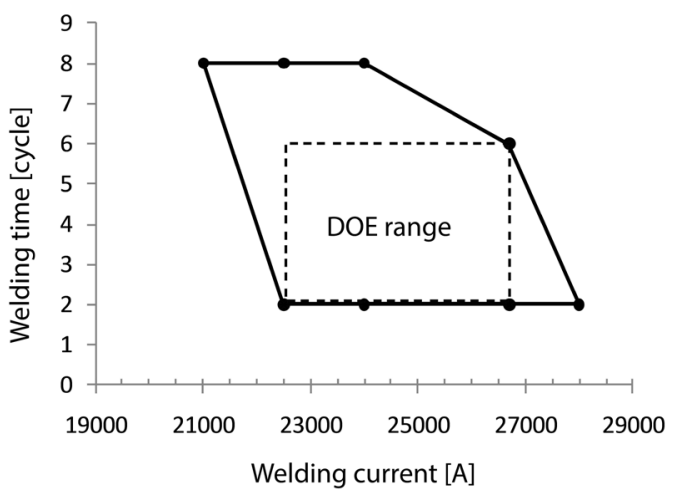

Fig. 4. Weldability region obtained via numerical and experimental results

(a)
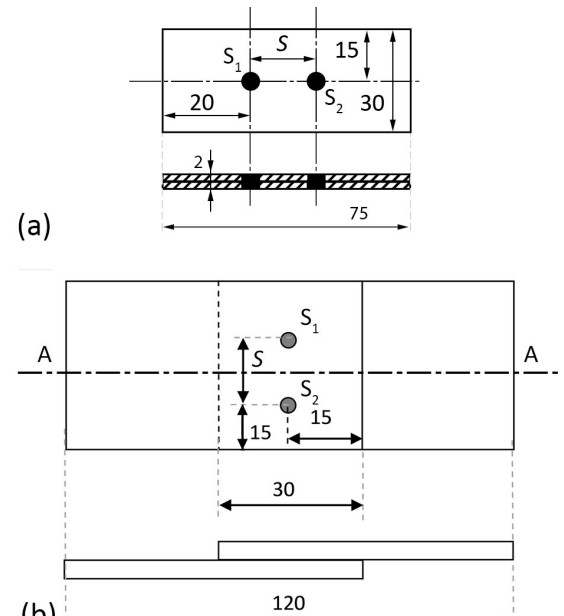

(b)

Fig. 5. Arrangement of spots for DOE; a) samples for nugget dimension checking, b) Samples for tensile-shear test; samples are cut along $A-A$ line to check spot strength; $S$ is distance (dimensions in $\mathrm{mm}$ ) 


\subsubsection{Tensile-Shear Tests}

Tensile-shear tests were performed inside the weldability range, after designing experiments for welding current, time, and distance. The specimens shown in Fig. 5 were first cut along the A-A line then they were implemented in the tensile testing machine to check the failure strength of the shunted nugget which was then converted to failure load using the nugget area.

Table 1. Chosen range of welding current and time for DOE

\begin{tabular}{lcc}
\hline \multicolumn{1}{c}{ Parameter } & Min & Max \\
\hline Welding Current $[\mathrm{kA}]$ & 22.5 & 26.7 \\
\hline Welding time [cycle] & 2 & 6 \\
\hline Weld spacing [mm] & 5 & 20 \\
\hline
\end{tabular}

Table 2. Average welding parameters for spot

\begin{tabular}{ccc}
\hline Current $[\mathrm{kA}]$ & Welding time [cycle] & Force $[\mathrm{kN}]$ \\
\hline 24 & 4 & 2.9 \\
\hline
\end{tabular}

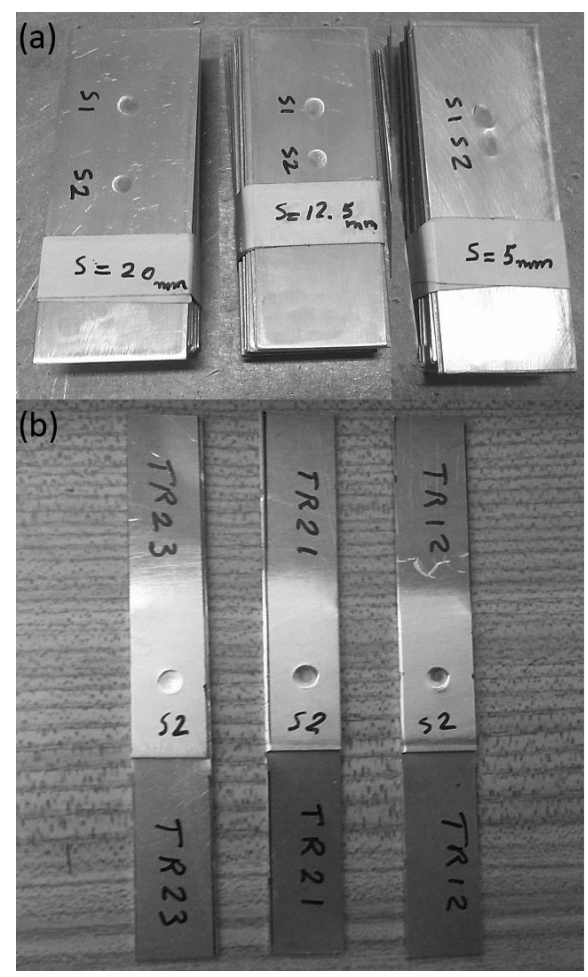

Fig. 6. Welded specimens for a) dimension checking, b) tensile-shear test (after cutting along A-A line)

\subsubsection{Equipment}

The welding procedure was performed using an RSW machine PFP 231 connected to a special device (TE1600) for checking electrical parameters, while tensile-shear tests were done using a Zwick-Roell Z250 machine. Cut specimens were then mounted for geometrical and metallurgical considerations under a light microscope (Olympus SZX9) while other samples were investigated with SEM (JEOL JSM7600F).

\section{RESULTS AND DISCUSSION}

Results are provided according to the following order:

- Considering predicted temperature distribution on the shunted nuggets and comparing them with micrographs,

- Considering predicted cooling rates on shunted nuggets and comparing them with mechanical quality in terms of presence of cracks, tensileshear strength, and failure types, using SEM images and tensile-shear test results.

\subsection{HAZ Development}

HAZ growth around the shunted nugget and between spots is considered numerically by checking temperature distribution, while it is discovered experimentally by investigation of shunted nugget micrographs.

\subsubsection{Predicted Temperature Distribution}

The temperature distribution for HAZ development between spots along $x$-axis on the faying surface is indicated in Fig. 7 during the cooling phase, about 1 cycle after the welding current is switched off. The asymmetry of temperature distribution is observed for both distances while it is severe for a shorter distance. Higher levels of temperatures appeared between the spots. This is an important cause of HAZ generation between spots with a bigger volume for $5 \mathrm{~mm}$ welding distance. Although asymmetry of temperature distribution is also observed for $20 \mathrm{~mm}$ welding distance, the level of temperatures does not cause the generation of HAZ, in comparison to the values calculated for the $5 \mathrm{~mm}$ welding distance between weld spots.

\subsubsection{HAZ Growth in Micrographs}

As shown in Fig. 8, the development of HAZ toward the previous nugget is indicated for nugget with a shorter welding distance (Fig. 8a). Shunted nugget size is also reduced due to shunting effect while the 
volume of HAZ is increased in the vertical direction versus nugget size compared to longer welding distance (Fig. 8b). This is a reasonable proof for the predicted temperature distribution obtained in Fig. 7 as temperature values between and over the spot during a cooling phase are adequate to generate HAZ in these domains.

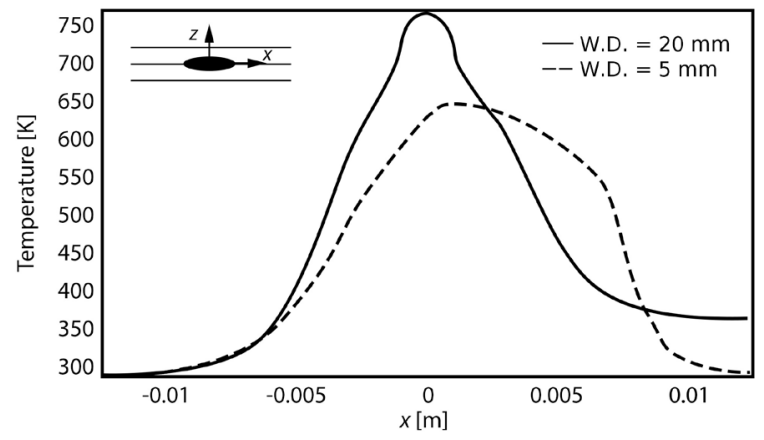

Fig. 7. Predicted temperature distribution during cooling phase for a) $5 \mathrm{~mm}$, and b) $20 \mathrm{~mm}$ weld spacing along $x$-axis on faying surface, with $25.3 \mathrm{kA}$ and 4 cycles welding current and time respectively; W.D. means welding distance
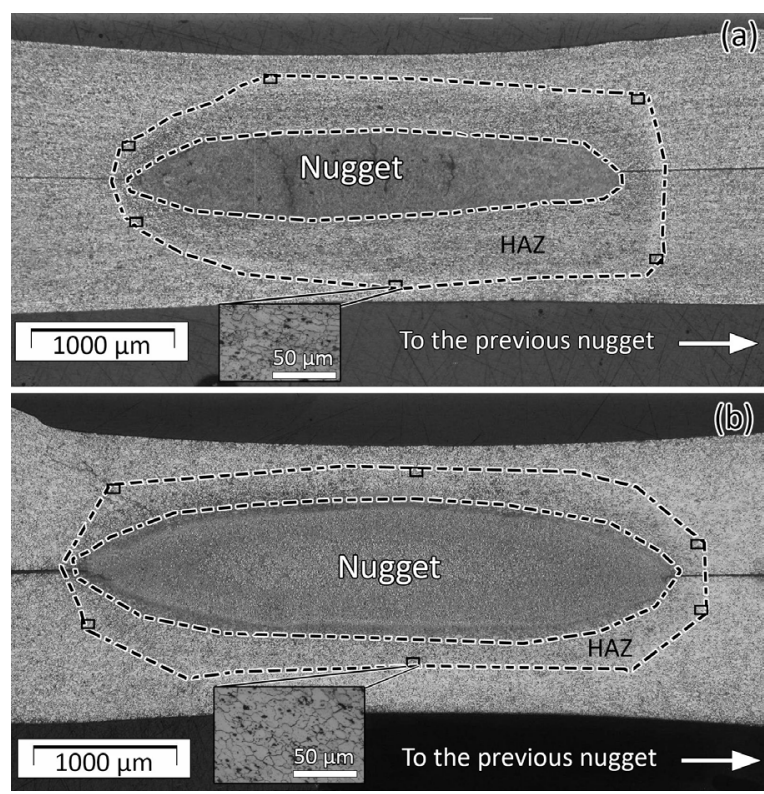

Fig. 8. Section of welding nugget for a) $5 \mathrm{~mm}$,

b) $20 \mathrm{~mm}$ weld spacing, for $25.3 \mathrm{kA}$ and 4 cycles welding current and time respectively; Rectangles indicate important places at which HAZ boundary is checked

The HAZ domain shown in Fig. 8 was measured using light microscope images around nugget with $500 \times$ magnification. Six important points at which the transition of HAZ to the base metal occurs are indicated in Fig. 8, while one of them is magnified.

\subsection{Brittleness and Strength Reduction}

Influence of welding distance on brittleness and reduction in tensile-shear strength of the shunted nugget is predicted by checking cooling rates of the nugget and the HAZ around it. This phenomenon is comprehensively considered by three different experimental investigations. Cracks are observed on SEM images, tensile-shear test results are investigated, and the failure types of nuggets are compared.

\subsubsection{Predicted Cooling Rates}

Cooling rates for shunted nuggets are calculated numerically at the centre of the nugget, for both welding distances (Fig. 9). The higher cooling rate is obtained for $20 \mathrm{~mm}$ welding distance, according to the FEM results for the centre point. The reason for indicating solidus temperature in Fig. 9 is the importance of this temperature which will be discussed more in the next section.

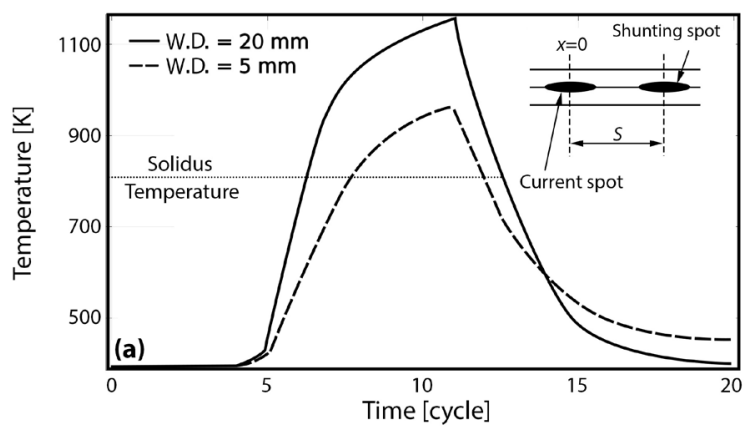

Fig. 9. Predicted cooling and heating rates for $x=0$ of current welding spot, for with $25.3 \mathrm{kA}$ and 4 cycles welding current and time respectively

Although the purpose of this study is to verify the prediction of temperature variation on the metallurgical and mechanical behaviour of AA2219 shunted RSW joints, the validity of temperature prediction has also been indirectly checked by considering power (heat) input. For checking the accuracy of temperature prediction, the linear relationship between the power input and maximum temperature obtained in the process (Yeung and Thornton [25]) was used. For this purpose, the power input of the welding process was checked for single and shunted spots, and the maximum temperature could have been estimated. Since this linear relationship is obtained for aluminium alloys, it is also currently reliable to be used for other aluminium alloys. 


\subsubsection{Experimental Effect of Predicted Cooling Rates}

As explained in the previous section, the experimental consideration of predicted cooling rates is performed by three different experiments, in terms of crack generation, tensile-shear strength, and failure type investigation.

\subsubsection{Crack Generation}

The temperature time transformation (TTT) diagram shown in Fig. 10 is indicating the phase transformations of $\mathrm{Al}$ 94- $\mathrm{Cu} 5.2$ (wt\%) alloy. Although AA2219 includes up to $0.5 \% \mathrm{Fe}$ and $0.2 \mathrm{Mn}$, it is reasonable to use this TTT diagram to consider major phase changes during the time for AA2219 with a composition obtained in Table B1. By using this diagram (Fig. 10), one can estimate the percentage of meta-stable $\theta^{\prime}$ phase and Guinier-Preston (GP) zones during the cooling process. Although all of these meta-stable phases will finally transform to stable $\alpha$ and $\theta$ phases after a certain sufficient time, the persistence of $\theta^{\prime}$ during cooling process might increase the brittleness of the nugget microstructure due to semi-coherent nature and lower strength, while the strength of GP zone is in higher levels [26]. Therefore, the possibility of crack generation could be associated with the percentages of meta-stable phases during cooling period.

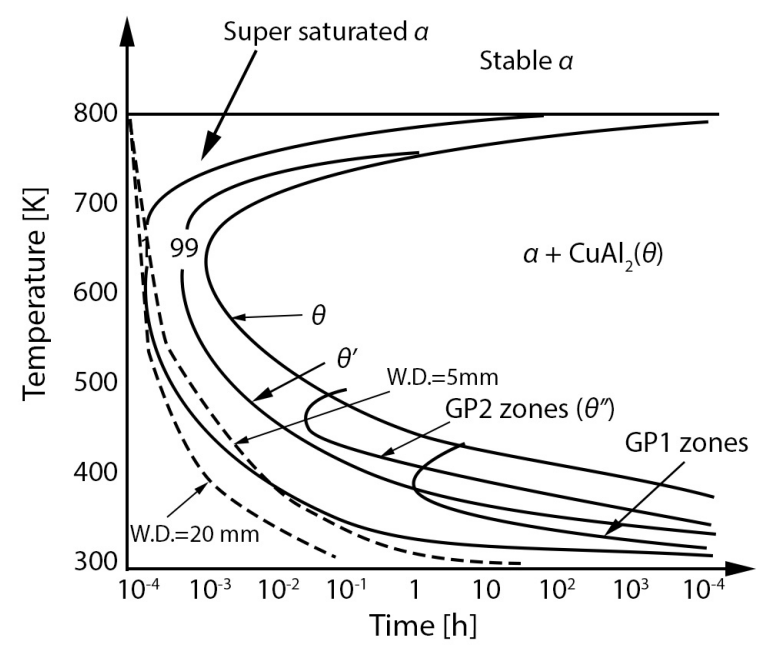

Fig. 10. TTT diagram of Al 94 - Cu 5.2\% (wt\%) [27], including cooling procedures predicted in Fig. 9.

Comparing the TTT diagram with predicted cooling rates (Fig. 9), shows more percentages of $\theta^{\prime}$ phase inside the nugget with $5 \mathrm{~mm}$ welding distance, while very less or zero percentage of meta-stable phases can be estimated in the nugget zone with 20 $\mathrm{mm}$ welding distance according to the TTT diagram in Fig. 10. Therefore, the brittleness and cracking possibility of nugget with a shorter welding distance could be more than nugget with a longer welding distance. This issue is checked experimentally by investigating cracks on SEM images (Fig. 11) in nuggets produced by different welding distances. As seen in Fig. 11a, cracks and even voids have appeared for shorter welding distances inside the nugget while few cracks are observed for longer distances (Fig. 11b).

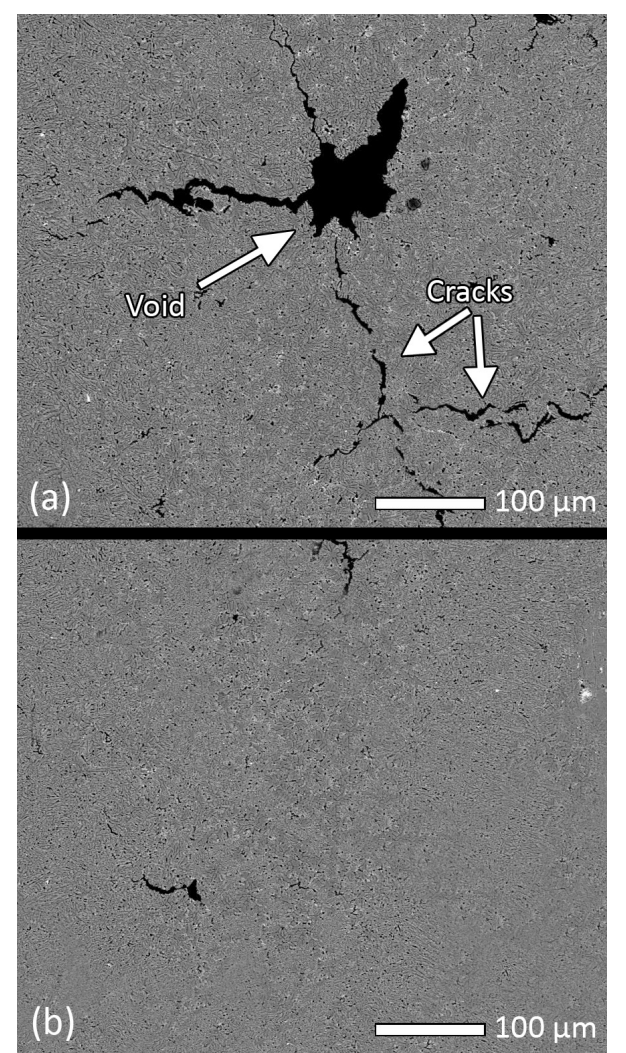

Fig. 11. SEM image of nugget for a) $5 \mathrm{~mm}$ and b) $20 \mathrm{~mm}$ weld spacing for $25.3 \mathrm{kA}$ and 4 cycles welding current and time respectively, with $150 \times$ magnification

Although this comparison is not about the effect of different percentages of $\mathrm{Cu}$ content in the alloy on brittleness, the difference between $\mathrm{Cu}$ content in the phases can effect this phenomenon, as shown in the study by Barlas and Colak [28]. This study could prove the increase in brittleness by increasing rich-copper particles in the content. It shows the concentration of more copper in microstructure increases the possibility of crack appearance. This is a logical conclusion as uneven distribution of copper over Al$\mathrm{Cu}$ alloy changes the mechanical and metallurgical 
behaviour of an alloy, as changing the percentages of different phases in the current alloy $\left(\alpha, \theta\right.$, and $\left.\theta^{\prime}\right)$ does the same. This is again proven in the study by Elatharasan and Kumar [29], about the corrosion analysis of AA 7075 for FSW products, as corrosion usually appeared near $\mathrm{Cu}$ inter-metallic particles, or the study by Matesa et al. [30] about the effect of heat treatment on impact energy as precipitation of intermetallic contents amplified the brittleness.

\subsubsection{Tensile-Shear Results}

Tensile-shear results also show the reduction of the tensile-shear strength of shunted nuggets. Fig. 12 indicates the failure load of the welding nugget under tensile-shear test versus the welding distance for certain welding current. A reduction in failure load is observed by reducing weld spacing. The reduction in welding distance has changed the thermal behaviour of the welding process in the way the shunted nugget and HAZ have become more brittle and easier to fracture. Therefore, it is reasonable to observe such tensile-shear behaviour from shunted nuggets. The behaviour observed in failure types of shunted nuggets after tensile-shear test in the next section is also in agreement with the latter result obtained for the tensile-shear test.

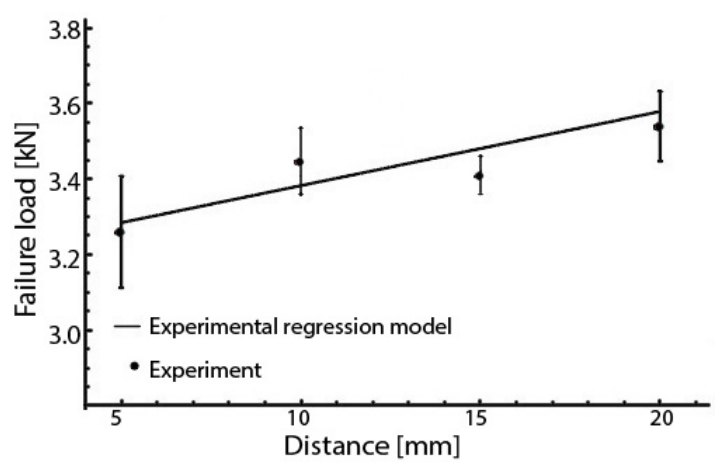

Fig. 12. Comparison of experimental and experimental regression model results of failure load versus weld spacing with $25.3 \mathrm{kA}$ and 4 cycles welding current and time respectively

\subsubsection{Failure Types of Shunted Nugget}

The SEM image of fractured shunted nugget after tensile-shear test with $5 \mathrm{~mm}$ welding distance (Fig. 13a) shows the interfacial and brittle failure of the shunted nugget while the presence of cracks inside the nugget is simply observable. This is different for the $20 \mathrm{~mm}$ welding distance as shown in Fig.13b. Although the sides of the fractured nugget seem to have a brittle type of crack due to a subtle shunting effect, a pull-out failure is observed. In addition, the
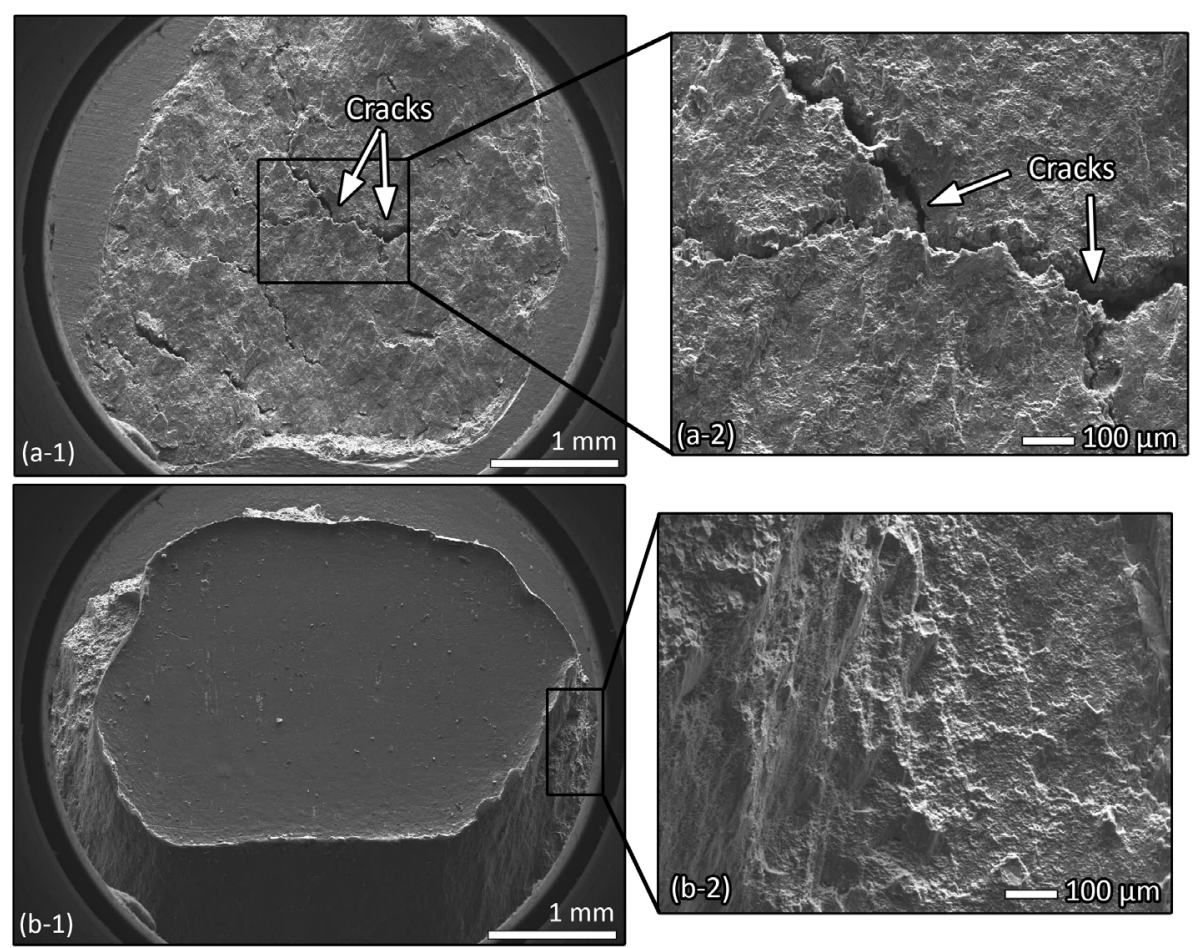

Fig. 13. SEM images showing the failure type of nuggets after tensile-shear test for a) $5 \mathrm{~mm}$, and b) $20 \mathrm{~mm}$ welding distance, with $25.3 \mathrm{kA}$ and 4 cycles welding current and time respectively with (1) $25 \times$, and (2) $100 \times$ magnification 
presence of initial cracks is rarely observed around the shunted nugget with $20 \mathrm{~mm}$ weld spacing.

The main reason for the difference in failure types is associated with the poorer metallurgical and mechanical quality of shunted nuggets. The initial cracks inside the nugget have initiated the interfacial failure inside the nugget for the $5 \mathrm{~mm}$ welding distance while the possibility of such phenomenon for the $20 \mathrm{~mm}$ welding distance is not considerable due to better mechanical and metallurgical conditions as discussed in previous sections.

\section{CONCLUSION}

The influence of shunting current on metallurgical and mechanical behaviour of resistance spot welded joints in AA2219 joints was analysed numerically and experimentally. The welding distance was chosen as the main variable of the problem to analyse the shunting effect. Temperature distribution and cooling rates after the application of welding current were checked numerically while verified with comparisons to the experimental results of metallographic micrographs, tensile-shear test results, and SEM images. Numerical and experimental results were in reasonable agreement while the following points are concluded:

- The growth of HAZ volume together with development toward the previous nugget was revealed while this issue was more intense for shorter welding distances.

- According to predicted cooling rates, brittleness of the structure of the shunted nugget and HAZ was discovered and could be associated with the presence of meta-stable incoherent phase during the cooling process for shorter welding distance while SEM images showed more cracks, with weaker tensile-shear strength.

- The checking failure type of shunted nuggets with different welding distances proved the presence of several cracks inside the nugget as a result of brittleness causing interfacial fractures for a shorter distance, while it was a pull-out failure for longer distance $(20 \mathrm{~mm})$ without critical cracks around the nugget. This indicates that $20 \mathrm{~mm}$ weld spacing could be an appropriate choice to obtain desirable quality for current material and welding conditions while designing limitations of intermittent RSW in terms of spot layout and efficient use of space can be respected.

\section{REFERENCES}

[1] Zeyveli, M., Özkan, M., Ulaş, H.B. (2012). An Investigation into the mechanical behavior of the St 37 sheet materials joined with clinching rivet. International Iron \& Steel Symposium, Karabuk. (in Turkish)

[2] Hard, A. R. (1948). Preliminary test of spot weld shunting in 24St Alclad. Welding Journal, vol. 27, no. 6, p. 491-495.

[3] Chang, H.S., Cho, H.S. (1990). A study on the shunt effect in resistance spot welding. Welding Journal, vol. 69, p. 308-316.

[4] Senkara, J., Zhang, H. (2000). Cracking in spot welding aluminum alloy AA5754. Welding Journal, vol. 79, p. 194s-201s.

[5] Zhang, H., Senkara, J., Wu, X. (2002). Suppressing cracking in resistance welding AA5754 by mechanical means. Journal of Manufacturing Science and Engineering, vol. 124, no. 1, p. 79-85, D0l:10.1115/1.1418693.

[6] Howe, P. (1994). Spot weld spacing effect on weld button size. Sheet Metal Welding $6^{\text {th }}$ Conference Proceedings, paper C03.

[7] Wang, B.L., Lou, M., Shen, Q., Li, Y. B., Zhang, H. (2013). Shunting effect in resistance spot welding steels - part 1: Experimental study. Welding Journal, vol. 92, no. 6, p. 182s-189s.

[8] Li, Y.B., Wang, B., Shen, Q., Lou, M., Zhang, H. (2013). Shunting effect in resistance spot welding steels - part 2: Theoretical analysis. Welding Journal, vol. 92, p. 231s-238s.

[9] Tsai, C.L., Jammal, O.A., Papritan, J.C., Dickinson, D.W. (1992). Analysis and development of a real time control methodology in resistance spot welding. Welding Journal, vol. 70, no. 12, p. 339s-351s.

[10] Shen, J., Zhang, Y., Lai, X., Wang, P.C. (2011). Modeling of resistance spot welding of multiple stacks of steel sheets. Materials \& Design, vol. 32, no. 2, p. 550-560, D0l:10.1016/j. matdes.2010.08.023.

[11] Nied, H.A. (1984). The finite element modeling of resistance spot welding process. Welding Journal, vol. 63 , no. 4, p. 123s-132s.

[12] Zhang, W. (2003). Design and implementation of software for resistance welding process simulations. Journal of Material and Manufacture, vol. 112, no. 5, p. 556-564, DOl:10.4271/2003-01-0978.

[13] Kim, J.H., Cho, Y., Jang, Y.H. (2013). Estimation of the weldability of single-sided resistance spot welding. Journal of Manufacturing Systems, vol. 32, no. 3, p. 505-512, DOI:10.1016/j.jmsy.2013.04.007.

[14] Hamedi, M., Eisazadeh, H., Esmailzadeh, M. (2010). Numerical simulation of tensile strength of upset welded joints with experimental verification. Material \& Design, vol. 31, no. 5, p. 2296-2304, D0I:10.1016/j.matdes.2009.12.011.

[15] Sun, X., Dong, P. (2000). Analysis of Aluminum resistance spot welding processes using coupled finite element procedures. Welding Journal, 215s-221s.

[16] Ghosh, A., Barman, N., Chattopadhyay, H., Hloch, S. (2013). A study of thermal behaviour during submerged arc welding. Strojniški vestnik - Journal of Mechanical Engineering, vol. 59, no. 5, p. 333-338, D0l:10.5545/sv-jme.2012.775. 
[17] Zhang, H., Senkara, J. (2011). Resistance Welding: Fundamentals and Applications, $2^{\text {nd }}$ ed., CRC Press, Boca Raton.

[18] Vogler, M., Sheppard, S. (1993). Electrical contact resistance under high loads and elevated temperature. Welding Journal, vol. 72, no. 6, p. 231s-238s.

[19] Kim, S., Lee, W., Kim, D. (2015). One-step distortion simulation of pulsed laser welding with multi-physics information. International Journal of Simulation Modelling, vol. 14, no. 1, p. 85-97, D0I:10.2507/IJSIMM14(1)8.291.

[20] MIL-W-6858D (1978). Military Specification-WeldingResistance: Spot and Seam. Department of the Air Force, Washington.

[21] Kearns, W.H. (ed.) (1997). Metals and Their Weldability, $7^{\text {th }}$ ed., vol. 4, American Welding Society, Miami.

[22] Saleem, J., Majid, A., Bertilsson, K., Carlberg, T., UI Islam, N. (2012). Nugget formation during resistance spot welding using finite element model. World Academy of Science - Engineering and Technology, vol. 67, p. 588-593.

[23] Jafari Vardanjani, M., Araee, A., Senkara, J., Jakubowski, J., Godek, J. (2016). Experimental and numerical analysis of shunting effect in resistance spot welding of Al2219 sheets. Bulletin of the Polish Academy of Sciences: Technical Sciences, vol. 64, no. 2, p. 425-434, D0l:10.1515/ bpasts-2016-0048.

[24] Yeung, K.S., Thornton, P.H., (1999). Transient thermal analysis of spot welding electrodes. Welding Journal, vol. 81, no. 1, p. $1 \mathrm{~s}-6 \mathrm{~s}$.

[25] Ashraf, S. M., Ahmed, S., Riaz, U. (2008). A Laboratory Manual of Metals and Alloys, p. 80-81, IK International, New Delhi.

[26] Porter, D.A., Easterling, K.E., Sherif, M. (2009). Phase Transformations in Metals and Alloys, 3rd ed., CRC Press, Boca Raton.

[27] Barles, Z., Çolak, M. (2014). Evaluation of the influence of upset stage on joint properties of friction welded dissimilar Aluminum-Copper cast alloys. Strojniški vestnik - Journal of Mechanical Engineering, vol. 60, no. 12, p. 832-837, DOl:10.5545/sv-jme.2014.1857.

[28] Elatharasan, G., Senthil Kumar, V.S. (2014). Corrosion analysis of friction stir-welded AA 7075 Aluminium alloy. Strojniški vestnik - Journal of Mechanical Engineering, vol. 60, no. 1, p. 29-34, D0I:10.5545/sv-jme.2012.711.

[29] Mateša, B., Samardžić, I., Dunđer, M. (2014). Heat treatment influence on clad dissimilar joints weakness. Tehnički vjesnik Technical Gazette, vol. 21, no. 5, p. 1035-1040.

[30] Hou, Z., Kim, I.S., Wang, Y., Li, C., Chen, C. (2007). Finite element analysis for the mechanical features of resistance spot welding process. Journal of Materials Processing Technology, vol. 185, no. 1-3, p. 160-165, Dol:10.1016/j. jmatprotec.2006.03.143.

[31] Sessler, J., Weiss, V. (1966). Aluminum alloy 2219, Muraca, R. F., Materials Data Handbook, 2nd ed., Western Applied Research \& Development, San Carlos.

[32] Rooy, E.L., Cayless, R.B.C., Bray, J.W. (1990). Nonferrous alloys and special-purpose materials. ASM International Handbook Committee, ASM Handbook - Properties \& selection, 10th Ed., vol. 2, ASM, $\mathrm{OH}$.

\section{APPENDICES}

Appendices include boundary conditions (Appendix A) and different material properties (Appendix B) used in finite element analysis.

\section{A Boundary Conditions}

All boundary conditions are provided in this appendix separately.

\section{A1 Electrical Boundary Conditions}

Table A1 includes electrical boundary conditions used in FEA section. In Table A1, $\phi_{e}$ is the electrical potential applied on the electrode and $\rho_{E S}$ is the electrical contact resistivity between the electrode and sheet, $\Delta \phi_{S S}$ is the voltage drop between the sheets, $\rho_{S S}$ is the electrical contact resistivity between the welds, and $\Delta \phi_{S h}$ is the voltage drop in the shunting nugget.

Table A1. Electrical boundary conditions

\begin{tabular}{lcc}
\hline Boundary & \multicolumn{1}{c}{ Equation } \\
\hline $\begin{array}{l}\text { Electrode-sheet } \\
\text { Interface [2] }\end{array}$ & $\frac{1}{\rho}\left(\frac{\partial \phi_{x, y, z}}{\partial z}\right)=\frac{1}{\rho_{E S}}\left(\phi_{e}-\phi_{x, y, z}\right)$, & (A1) \\
\hline $\begin{array}{l}\text { Faying surface } \\
\text { [2] }\end{array}$ & $\frac{1}{\rho}\left(\frac{\partial \phi_{x, y, z}}{\partial z}\right)=\frac{1}{\rho_{S S}}\left(\Delta \phi_{S S}\right)$, \\
\hline $\begin{array}{l}\text { Surfaces } \\
\text { exposed to air }\end{array}$ & $\frac{1}{\rho}\left(\frac{\partial \phi_{x, y, z}}{\partial z}\right)=0$, \\
\hline $\begin{array}{l}\text { Perimeter of } \\
\text { shunting nugget }\end{array}$ & $\frac{1}{\rho}\left(\frac{\partial \phi_{x, y, z}}{\partial z}\right)=\frac{1}{\rho_{S h}}\left(\Delta \phi_{S h}\right)$. \\
\hline
\end{tabular}

\section{A2 Thermal Boundary Conditions}

Table A2 includes thermal boundary conditions used in FEA. In Table A2 $k_{E S}$ and $k_{S S}$ are TCC coefficient of electrode-sheet interface and sheets, respectively; $T_{W}$ and $T_{A}$ are water and ambient temperature, respectively; $h_{W}$ and $h_{A}$ are thermal convection coefficient of water and air respectively, and $n$ is the surface normal vector.

Table A2. Thermal boundary conditions

\begin{tabular}{lcl}
\hline Boundary & Equation \\
\hline $\begin{array}{l}\text { Contact surface } \\
\text { of electrode and } \\
\text { sheet [2] }\end{array}$ & $-k_{E S} \frac{\partial T_{x, y, z}}{\partial z}=\frac{1}{\rho_{E S}}\left(\phi_{x, y, z}-\phi_{e}\right)^{2}$, & (A5) \\
\hline
\end{tabular}




\begin{tabular}{ll}
\hline $\begin{array}{l}\text { Faying surface } \\
\text { [2] }\end{array}$ & $-k_{S S} \frac{\partial T_{x, y, z}}{\partial z}=\frac{1}{\rho_{S S}}(\Delta \phi)^{2}$, \\
\hline $\begin{array}{l}\text { Inside electrode } \\
\text { exposed to } \\
\text { water }\end{array}$ & $-k_{e} \frac{\partial}{\partial z} T_{x, y, z}=h_{W}\left(T_{x, y, z}-T_{W}\right)$, \\
\hline $\begin{array}{l}\text { Sheet, exposed } \\
\text { to ambient }\end{array}$ & $-k \frac{\partial}{\partial z} T_{x, y, z}=h_{A}\left(T_{x, y, z}-T_{A}\right)$, \\
\hline $\begin{array}{l}\text { Unspecified } \\
\text { surfaces }\end{array}$ & $\frac{\partial T}{\partial n}=0$. \\
\hline
\end{tabular}

\section{B Material Composition Properties}

This appendix provides all of the material composition and properties used in FEA and discussion.

\section{B1 AA2219}

The material composition of AA2219 identified by SEM is provided in Table B1. The functions or values of material properties used for aluminium alloy 2219 are provided in Tables B2 and B3.

Table B1. AA2219 element composition

\begin{tabular}{lccccc}
\hline Spectrum & $\mathrm{Cu}$ & $\mathrm{Al}$ & $\mathrm{Mg}$ & $\mathrm{Mn}$ & $\mathrm{Fe}$ \\
\hline Spectrum 1 & 5.02 & 93.53 & 1.17 & 0.53 & 0.25 \\
\hline Spectrum 2 & 5.25 & 92.67 & 1.25 & 0.56 & 0.27 \\
\hline Spectrum 3 & 5.21 & 92.80 & 1.29 & 0.50 & 0.20 \\
\hline
\end{tabular}

Table B2. Different material properties for AA2219-T6, as a function of temperature

\begin{tabular}{|c|c|c|}
\hline Property & Equation & \\
\hline $\begin{array}{l}\text { Density }\left[\mathrm{kg} / \mathrm{m}^{3}\right] \\
{[31]}\end{array}$ & $D(T) \cong 0.0002 T^{2}-0.17 T+2858.3$ & (B1) \\
\hline $\begin{array}{l}\text { Electrical } \\
\text { resistivity } \\
{[\Omega \cdot \mathrm{m}][32]} \\
\end{array}$ & $\begin{array}{l}\rho(T)=5.7 \times 10^{-8} \times \\
\times(1+0.0017 \times(T-293)),\end{array}$ & (B2) \\
\hline $\begin{array}{l}\text { Linear thermal } \\
\text { expansion }[1 / \mathrm{K}] \\
{[31]}\end{array}$ & $\alpha(T) \cong(0.0063 T+19.708) \times 10^{-6}$ & (B3) \\
\hline $\begin{array}{l}\text { Specific heat } \\
\text { capacity } \\
{[\mathrm{J} /(\mathrm{kg} \cdot \mathrm{K})][33]}\end{array}$ & $c(T) \cong-0.0016 T^{2}+1.3521 T+567.72$ & (B4) \\
\hline $\begin{array}{l}\text { Thermal } \\
\text { conduction } \\
\text { coefficient } \\
{[\mathrm{W} /(\mathrm{m} \cdot \mathrm{K})][33]}\end{array}$ & $k(T) \cong 0.1836 T+71.847$ & (B5) \\
\hline $\begin{array}{l}\text { Elasticity } \\
\text { Modulus [GPa] } \\
\text { [33] }\end{array}$ & $\begin{array}{l}E(T) \cong 2 \times 10^{-7} T^{3}-0.0005 T^{2}+ \\
+0.2253 T+43.386\end{array}$ & (B6) \\
\hline $\begin{array}{l}\text { Yield Strength } \\
{[\mathrm{MPa}][31]}\end{array}$ & $\begin{array}{l}\sigma_{e}(T) \cong 7 \times 10^{-6} T^{3}-0.0102 T^{2+} \\
+4.0876 T+126.96\end{array}$ & (B7) \\
\hline
\end{tabular}

Table B3. Important temperature independent properties of AA2219-T6

\begin{tabular}{lc}
\hline Parameter & Value \\
\hline Solidus temperature $\left[{ }^{\circ} \mathrm{C}\right][31]$ & 543 \\
\hline Liquidus temperature $\left[{ }^{\circ} \mathrm{C}\right][31]$ & 643 \\
\hline Fusion heat $[\mathrm{kJ} / \mathrm{kg}][32]$ & 389 \\
\hline
\end{tabular}

\section{B2 C18150}

The functions or values of $\mathrm{C} 18150$ properties are provided in Table B4.

Table B4. Different material properties for C18150, as a function of temperature

\begin{tabular}{|c|c|c|}
\hline Property & Equation & \\
\hline $\begin{array}{l}\text { Linear thermal } \\
\text { expansion }[1 / \mathrm{K}][8]\end{array}$ & $\begin{array}{l}\alpha_{E}(T) \cong\left(3 \times 10^{-6} T^{2}+0.0013 T+\right. \\
+15.934) \times 10^{-6}\end{array}$ & (B8) \\
\hline $\begin{array}{l}\text { Electrical resistivity } \\
{[\Omega \cdot \mathrm{m}][8]}\end{array}$ & $\begin{array}{l}\rho_{E}(T) \cong\left(10^{-5} T^{2}+0.0009 T+\right. \\
+1.3754) \times 10^{-8}\end{array}$ & (B9) \\
\hline $\begin{array}{l}\text { Specific heat capa- } \\
\text { city }[\mathrm{J} /(\mathrm{kg} \cdot \mathrm{K})][8]\end{array}$ & $\begin{array}{l}c_{E}(T) \cong 8 \times 10^{-5} T^{2}+ \\
+0.0726 T+369.7\end{array}$ & (B10) \\
\hline $\begin{array}{l}\text { Thermal conduction } \\
\text { coefficient } \\
{[\mathrm{W} /(\mathrm{m} \cdot \mathrm{K})][8]}\end{array}$ & $\begin{array}{l}k_{E}(T) \cong-2 \times 10^{-5} T^{2}- \\
-0.1147 T+424.89\end{array}$ & (B11) \\
\hline $\begin{array}{l}\text { Elasticity modulus } \\
{[\mathrm{GPa}][8]}\end{array}$ & $\begin{array}{l}E_{E}(T) \cong 10^{-7} T^{3}-0.0002 T^{2}- \\
-0.0516 T+150.81,\end{array}$ & (B12) \\
\hline $\begin{array}{l}\text { Yield strength } \\
{[\mathrm{MPa}][8]}\end{array}$ & ( & (B13) \\
\hline
\end{tabular}

Note: $T$ is temperature in $\mathrm{K}$.

\section{B3 Shunting Nugget}

Important properties of shunting nugget are provided in Table B5.

Table B5. Important electrical and mechanical properties of shunting nugget

\begin{tabular}{lc}
\hline Parameter & Value \\
\hline Electrical resistivity $[\Omega \cdot \mathrm{m}]$ & $7.11 \times 10^{-8}$ \\
\hline Elasticity modulus $[\mathrm{GPa}]$ & 75 \\
\hline Yield Strength $[\mathrm{MPa}]$ & 342 \\
\hline
\end{tabular}

\section{B4 Contact Properties}

ECR values are shown in Table B6.

Table B6. ECR values, at room temperature

\begin{tabular}{lc}
\hline Parameter & Value \\
\hline ECR of sheets $[\Omega]$ & $6.8 \times 10^{-5}$ \\
\hline ECR of electrode-sheet $[\Omega]$ & $8.1 \times 10^{-7}$ \\
\hline
\end{tabular}

